\title{
Trends in Establishment Survey Nonresponse Rates and Nonresponse Bias: Evidence from the 2001-2017 IAB Establishment Panel
}

\author{
Corinna König ${ }^{1}$, Joseph W. Sakshaug ${ }^{1}$, Jens Stegmaier ${ }^{1}$, and Susanne Kohaut ${ }^{1}$
}

\begin{abstract}
Evidence from the household survey literature shows a declining response rate trend in recent decades, but whether a similar trend exists for voluntary establishment surveys is an understudied issue. This article examines trends in nonresponse rates and nonresponse bias over a period of 17 years in the annual cross-sectional refreshment samples of the IAB Establishment Panel in Germany. In addition, rich administrative data about the establishment and employee composition are used to examine changes in nonresponse bias and its two main components, refusal and noncontact, over time. Our findings show that response rates dropped by nearly a third: from $50.2 \%$ in 2001 to $34.5 \%$ in 2017 . Simultaneously, nonresponse bias increased over this period, which was mainly driven by increasing refusal bias whereas noncontact bias fluctuated relatively evenly over the same period. Nonresponse biases for individual establishment and employee characteristics did not show a distinct pattern over time with few exceptions. Notably, larger establishments participated less frequently than smaller establishments over the entire period. This implies that survey organizations may need to put more effort into recruiting larger establishments to counteract nonresponse bias.
\end{abstract}

Key words: Survey participation; establishment characteristics; administrative data; unit nonresponse.

\section{Introduction}

Establishment surveys are indispensable tools for investigating economic relationships and providing up-to-date information about the labor market. Collecting information about the labor market while gaining deeper insights into the economic status of establishments and employee conditions are major goals of these surveys. By measuring a variety of topics, such as employment development, investments, and vocational education, economic research can be enhanced and new correlations and developments observed. This feeds into academic and non-academic discussions of the economic climate and informs important policy decisions. Although many establishment surveys are mandatory whereby participation is required by law, voluntary establishment surveys continue to play a key role in informing official statistics and policy development.

There are several prominent examples of voluntary establishment surveys. One example is the European Company Survey (ECS) (Eurofound 2015). The ECS provides Europeanand country-specific information on work organization, human resource management, and

\footnotetext{
${ }^{1}$ Institute for Employment Research, 104 Regensburger Straße, Nuremberg 90478, Germany. Emails: corinna.koenig@iab.de, joe.sakshaug@iab.de, jens.stegmaier@iab.de, and susanne.kohaut@iab.de
} 
workplace innovations. Since 2004, telephone interviews are conducted every four to five years in up to 32 countries with establishments of all industries. The results contribute to policy discussions at both the employer- and employee-level as representatives of both levels are interviewed. In the United States, a large producer of establishment surveys is the Bureau of Labor Statistics (BLS), which conducts numerous voluntary and mandatory surveys that vary in their frequency (e.g., monthly, quarterly, annual) and design. The largest voluntary BLS survey is the Current Employment Statistics survey, which interviews about 145,000 businesses and government agencies monthly. The survey produces information on non-farm employment, hours, and earnings for employees in each state, which is used to generate monthly payroll estimates (Mullins 2016). A further example of a large, voluntary establishment survey - and the focus of the present study - is the IAB Establishment Panel in Germany, conducted by the Institute for Employment Research (IAB). About 16,000 establishments are interviewed annually via face-to-face for the purpose of studying the demand side of the labor market and collecting information about the establishment structure, as well as financial characteristics and employee attributes. Furthermore, the survey captures challenges and future assessments of establishments to inform policy debates on measures that facilitate economic growth (Ellguth et al. 2013). Collective bargaining coverage is another important topic of the survey, which is repeatedly discussed by politicians in Germany (Ellguth and Kohaut 2019).

Like all surveys, one of the largest threats to establishment survey data quality is unit nonresponse. For establishments, survey participation is largely a business decision. Unlike social surveys that might appeal to households for intrinsic, altruistic, or topical reasons, people in the establishments must evaluate whether they have the authority, capacity, and motivation to participate in a voluntary survey, which takes resources away from their primary business objectives (Tomaskovic-Devey et al. 1995; Willimack et al. 2002; Willimack and Snijkers 2013). This decision might be affected by the organizational structure and available staffing, which are also key characteristics that surveys attempt to measure. Thus, there is reason to believe that nonresponse is a non-random process and, as a consequence, may introduce nonresponse bias in establishment survey estimates.

Although response rates for household surveys have declined in recent decades (e.g., Luiten et al. 2020; Beullens et al. 2018; Brick and Williams 2013; De Leeuw and De Heer 2002; Groves and Couper 1998), response rate trends in voluntary establishment surveys and associated estimates of nonresponse bias are largely understudied. In this article, we investigated nonresponse trends in the IAB Establishment Panel over 17 years. The Panel is a unique data source for studying nonresponse trends over time as large cross-sectional refreshment samples are drawn each year to replenish the panel. In addition, the Panel can be directly linked to establishment-level characteristics derived from rich administrative data, which we exploited to study nonresponse bias trends and obtain a better understanding of the characteristics that correlate with nonresponse.

The remainder of the article is structured as follows. In Section 2, we briefly review theoretical frameworks of establishment survey participation, summarize the existing literature on response rates and correlates of participation, and present the research questions. In Section 3, the survey and administrative data sources used to study nonresponse are described. Section 4 details the analysis procedures and Section 5 presents outcome rates, nonresponse biases, and results from regression models of survey 
participation for each of the 17 years. In Section 6, the main findings of the study are summarized and their implications for survey practice are discussed.

\section{Background}

\subsection{Theoretical Frameworks of Establishment Survey Participation}

In general, answering a questionnaire of a voluntary survey is a work task that does not contribute to the establishment's primary goal of maximizing revenue (Sudman et al. 2000). Hence, to obtain cooperation from establishments, the actual and perceived response burden should be sufficiently low. Actual response burden corresponds to the costs incurred by the establishment while responding to the survey, which are never completely removed. In this context, the expectations regarding the response process are important. Especially for establishments that are recruited for the first-time, participation implies a high cognitive burden and a large time expenditure as they have no prior knowledge about the survey process or questionnaire.

Willimack et al. (2002) developed a framework that classifies individual factors associated with the participation decision into two groups according to the survey organization's ability to influence them. The first group includes factors that are out of the survey organization's control: the external environment, the establishment, and the respondent delegated the response task. The second group of factors are under the control of the survey organization and mainly concern the survey design. Willimack et al. (2002) also noted the three key features of authority, capacity, and motivation to respond, as originally defined by Tomaskovic-Devey et al. (1995). Authority refers to both the formal and informal authorization to decide whether to participate. Capacity refers to the ability of the respondent to successfully complete the questionnaire in terms of cognition, time, and data access. Lastly, the motivation to respond is related to the willingness of the respondent to undertake the response task. A representative of an establishment and the establishment itself must possess these features in order to respond to a survey request.

An extension of the Willimack et al. (2002) model was proposed by Willimack and Snijkers (2013), which shows the causal order of the decision-making process. For example, the establishment's management may consider the external environment when deciding whether to participate, which happens before appointing the responding employee. The authors also argued that the dimensions of authority, capacity, and motivation to respond can be applied to each of the participation factors identified by Willimack et al. (2002).

\subsection{Response Rate Trends in Establishment Surveys}

When evaluating and comparing response rates of different establishment surveys, it is important to keep in mind that surveys differ in their design (e.g., mode of data collection, nonresponse follow-up), which can influence the response rate. In addition, mandatory surveys are expected to have higher response rates and different trends compared to voluntary ones (Petroni et al. 2004; Paxson et al. 1995). In the following review of response rate trends, we focus on voluntary surveys. 
Christianson and Tortora (1995) interviewed 21 national statistical institutes in 16 countries to classify response rate trends for their establishment surveys and censuses as either increasing, decreasing, or unchanged over the past ten years of the respective studies. Information about 104 surveys was collected and anonymized, but no distinction was made between mandatory and voluntary studies. The authors found that most surveys and censuses (about $41 \%$ ) observed no changes in response rates in the past ten years. In addition, similar proportions of surveys and censuses reported increasing (27\%) and decreasing $(26 \%)$ response rates, while the remainder $(6 \%)$ provided no information. The authors mention possible reasons for increasing (or stable) response rates, including greater nonresponse follow-up efforts (e.g., use of reminders) and shortening of the questionnaire. Reasons for decreasing response rates included long questionnaires, sensitive questions about financial data, and diminishing survey budgets.

Among seven voluntary establishment surveys conducted by the BLS between 2010 and 2019, four showed decreasing response rate trends, while all others revealed no significant changes (https://www.bls.gov/osmr/response-rates/establishment-survey-response-rates.htm\# BLStable_2020_4_27_14_11_footnotes). Among those with a declining trend, the average decline over the ten years was about $7 \%$ with a range between $4-10 \%$ (own calculations).

For three waves of the ECS, 14 out of 21 countries (e.g., Belgium, France, Germany, Hungary, Slovenia) observed increasing response rates between 2004 and 2013. The average increase was $20 \%$ with a range between $3-45 \%$ and dominated by increases in Hungary (45\%), Slovenia (43\%), and Luxembourg (33\%). Five countries reported declining response rates over the same period, with a range between $8-25 \%$ and an average decline of $14 \%$. Countries with the largest decline included Finland (25\%) and Denmark (20\%). The two remaining countries, Latvia and the Netherlands, showed no change in their response rates. These differences in response rate trends occurred despite efforts to standardize the survey design, as all countries used the same survey methods (e.g., use of advance letters/emails, and minimum number of contact attempts) whenever possible (Eurofound 2015).

In addition to descriptive response rate trends, a key question is whether such trends correlate with nonresponse bias, as there is no guarantee that decreasing response rates are accompanied by increasing nonresponse bias over time, or vice versa. As yet, extensive calculations of nonresponse bias in establishment surveys have been neglected. Borrowing from the social survey literature (Brick and Tourangeau 2017; Groves and Peytcheva 2008; Groves 2006), a rather weak correlation between nonresponse rates and (absolute relative) nonresponse bias across several surveys has been identified. However, it is unknown whether a similarly weak correlation exists for establishment surveys.

\subsection{Correlates of Establishment Survey Participation}

Several studies have identified correlates of participation in voluntary establishment surveys. We focus on establishment-level correlates. For a discussion of other correlates (e.g., interviewer characteristics, competing survey requests, statutory laws regarding vacation/working days), see Janik and Kohaut (2012), Janik (2011), Seiler (2010), and Davis and Pihama (2009).

Tomaskovic-Devey et al. (1995) analyzed businesses as part of the 1989 North Carolina Employment and Health Survey and found that larger establishments and establishments 
in industries with higher average profits were less likely to respond. Likewise, Earp et al. (2018) ascertained with the 2012 Job Openings and Labor Turnover Survey of the BLS that small establishments with less than 50 employees respond at a higher rate in the first wave of a panel than larger establishments.

Phipps and Toth (2012) found in the BLS Occupational Employment Survey that the population size of the area where the establishment was located had a negative effect on the response rate. That is, establishments located in a city of one million or more inhabitants were less likely to respond. Additionally, they showed that large establishments had lower response likelihoods than smaller ones, and single-unit establishments were more likely to respond than multi-unit establishments. Overall, the lowest likelihood of response was observed for large multi-unit establishments in the information, finance, or professional/business services industries.

Janik (2011) and Janik and Kohaut (2012) investigated the correlation of establishment features and survey participation in the IAB Establishment Panel. Both studies reported that large establishments are less likely to participate, in line with the already-mentioned studies. Janik (2011) also found that establishments in East Germany are more likely to participate than those in West Germany.

While informative, the above studies are limited, in the sense that they analyze data of only one year or a short time period. What is missing from the literature is an extended analysis of temporal changes in establishment-level correlates over several years, which can inform whether compositional differences between respondents and nonrespondents are changing, and identify underrepresented groups that might require greater recruitment effort and/or targeted interventions going forward. We address this research gap by studying temporal changes in establishment-level correlates over 17 years of cross-sectional samples in the IAB Establishment Panel. In addition to establishment-level characteristics analyzed in previous studies, we also consider the demographic employee structure of the establishment (e.g., the share of women or employees with certain education levels). Such characteristics have not previously been examined in the nonresponse literature, but may provide a more detailed picture of the selectivity of establishment survey participation.

\subsection{Research Questions}

Although response rate trends are a simple, yet important descriptor of surveys, they are relatively understudied for voluntary establishment surveys, particularly in recent decades. In addition, a discussion of refusal and noncontact rates is missing and their consideration is relevant since overall response rate trends may be driven by differential trends in one or both factors (Groves and Couper 1998). We contribute to this research gap by answering the first research question:

(1) Have participation outcome rates (nonresponse, refusal, noncontact) in the IAB Establishment Panel's cross-sectional samples changed over time?

Even if overall response rate trends have changed over time, it reveals nothing about trends in the composition of the responding sample and the magnitude of potential nonresponse bias. Petroni et al. $(2004,15)$ emphasize that nonresponse bias may be a greater problem in establishment surveys than in household surveys as their " [ . . .] underlying population is very skewed" in terms of their attributes. However, there is a lack of extended evaluations of 
nonresponse bias in establishment surveys and their potentially dynamic behavior over time. Thus, it is unclear whether nonresponse biases are correlated with trends in the nonresponse rate. Furthermore, to the best of our knowledge, no study has separately analyzed refusal bias and noncontact bias trends for establishment surveys. Hence, the second research question is:

(2) How large are nonresponse biases in the IAB Establishment Panel's cross-sectional surveys and has their magnitude increased, decreased, or remained stable over time? Are nonresponse rate trends correlated with nonresponse bias?

Lastly, we analyze characteristics of establishments that may be related to survey participation and the potential changes in the magnitude of their relationship over time. Until now, almost all previous studies investigating correlates of establishment survey participation used only one year of data with a limited set of predictors. We extend this approach by using data for 17 years (from 2001 to 2017) to examine changes in associations, and consider a rich set of participation determinants, including general establishment characteristics and the employee structure of establishments. This leads to our third research question:

(3) To what extent are general establishment characteristics as well as employee characteristics of establishments associated with survey participation? Does the magnitude of these associations change over time?

\section{Data}

\subsection{IAB Establishment Panel - Refreshment Samples}

The IAB Establishment Panel is a voluntary annual longitudinal survey of establishments that gathers high quality data on labor demand in Germany. The questionnaire topics cover objective operational characteristics (e.g., employment indicators) as well as subjective assessments. The survey data influence government decisions at the federal and statelevels through consultation with the IAB and external researchers. The target population consists of every establishment in Germany with at least one employee who was liable for social security contributions on June 30 in the previous year.

Since 2001, approximately 16,000 establishments participated in the survey each year. The survey is composed of two samples. One sample consists of establishments who already participated in at least one of the last two waves and are approached for reinterview, and the second sample is a cross-sectional refreshment sample of establishments who are newly-recruited to join the panel (Fischer et al. 2008). We focus solely on the cross-sectional samples from 2001 to 2017 . The panel is mainly carried out by face-to-face interviewing with a small proportion of data collection by mail until 2015 in two federal states (Ellguth et al. 2013). We excluded the mail cases and restricted the analysis to samples assigned to face-to-face interviewing only.

Across the 17 years, a total of 124,395 establishments were selected for the annual refreshment samples, an average of about 7,317 new establishments per year (range: 4,619 in 2002 to 9,812 in 2017). An advance letter was sent to all sampled establishments announcing the survey and the impending interviewer visit and included sponsorship letters by high-ranking authorities (Fischer et al. 2008). Interviews were sought with the owner or manager of the establishment. The survey organization, which pays its 
interviewers per interview, determined how many contact attempts were made until a case was closed without an interview.

\subsection{IAB Administrative Data}

To evaluate nonresponse bias and identify correlates of participation, we utilized IAB administrative data. The data contain all establishments in Germany with at least one employee who was liable for social security contributions on June 30 in the previous year (Schmucker et al. 2018). The data also contain variables on numerous properties of the establishments and their workforce. For example, the number of employees by different education levels, age groups, and types of employment. Further information on this resource can be found in Schmucker et al. (2018). To use the administrative data, we performed a one-to-one linkage to the survey data, which is possible through a unique identifier. The current year of the IAB Establishment Panel is linked to the previous year of the administrative data since that is when the cross-sectional sample was drawn.

\subsection{Variables of Interest}

\subsubsection{Participation Outcomes}

Participation in the IAB Establishment Panel is defined as any establishment that completed the questionnaire with an interviewer in a face-to-face situation. If nonresponse occurred, interviewers were instructed to document reasons why a completed interview could not be obtained. Based on this paradata, the sample units were classified as respondents, refusals, and noncontacts. Online supplemental material Table S1 displays the categorization of the possible participation outcomes.

\subsubsection{Administrative Establishment Variables}

All administrative establishment variables used in the bias and regression analyses include the value observed at the time of sampling (i.e., approximately one year before the start of survey data collection). Table 1 shows the variables and their categories used in each analysis. The variables describing the establishments are summarized into two groups: general characteristics and employee structure. The general characteristics group contains the following variables: location, size, industry, year of foundation, change in the number of employees since the previous year, and the population size of the establishment's area. For the employee structure group, the variables include: shares of female employees, German employees, average age of employees, low-qualified employees, middle-qualified employees, and high-qualified employees. These variables were chosen based on their usage in previous substantive and methodological research on establishments, as well as their likely association with the survey topics (Sakshaug et al. 2019b; Brixy et al. 2007; Henze 2014; Wagner 2012), which make them suitable proxy indicators of nonresponse bias in the actual survey variables. Descriptive statistics for all variables are presented in online supplemental material Table S2. Interviewer characteristics were not analyzed as they are unavailable for the entire observation period from 2001 to 2017.

All variables were categorized to facilitate interpretation. In most cases, the categorization was performed arbitrarily based on uniform allocation of units into 
Table 1. Administrative variables and categories used in the bias and regression analyses.

\section{Categories}

Variable

Bias analysis

Regression analysis

General characteristics

\begin{tabular}{|c|c|c|}
\hline Location & $\begin{array}{l}\text { (0) East Germany } \\
\text { (1) West Germany }\end{array}$ & $\begin{array}{l}\text { (1) East Germany (REF) } \\
\text { (2) South Germany } \\
\text { (3) North Germany } \\
\text { (4) West Germany }\end{array}$ \\
\hline Establishment & (1) $1-9$ & (1) $1-4$ (REF) \\
\hline size (number & (2) $10-49$ & (2) $5-9$ \\
\hline of employees) & (3) $50+$ & (3) $10-19$ \\
\hline & & (4) $20-49$ \\
\hline & & (5) $50-99$ \\
\hline & & (6) $100-199$ \\
\hline & & (7) $200-499$ \\
\hline & & (8) 500-999 \\
\hline & & (9) $1,000+$ \\
\hline Industry & $\begin{array}{l}\text { (1) Agriculture/production } \\
\text { (2) Service }\end{array}$ & $\begin{array}{l}\text { (1) Agriculture/mining/energy/ } \\
\text { water }\end{array}$ \\
\hline & (3) Public/educ/health/arts & $\begin{array}{l}\text { (2) Manufacturing industry } \\
\text { (REF) }\end{array}$ \\
\hline & & (3) Construction industry \\
\hline & & (4) Trade/repair \\
\hline & & (5) Transport/communication \\
\hline & & $\begin{array}{l}\text { (6) Financial intermediation } \\
\text { (7) Services mainly for }\end{array}$ \\
\hline & & companies \\
\hline & & (8) Other services \\
\hline & & (9) Public sector \\
\hline Year of & (1) $1970 \mathrm{~s} / 1980 \mathrm{~s}$ & (1) $1970 \mathrm{~s} / 1980 \mathrm{~s}$ \\
\hline foundation & (2) $1990 \mathrm{~s}$ & (2) $1990 \mathrm{~s}$ \\
\hline & (3) $2000 \mathrm{~s}$ & (3) 2000s (REF) \\
\hline & (4) Unknown & (4) Unknown \\
\hline Change in the no. of & - & (1) Decrease \\
\hline employees since & & (2) No change (REF) \\
\hline previous year & & (3) Increase \\
\hline & & (4) Unknown \\
\hline Area population & - & $(1)<2,000$ \\
\hline size(number & & (2) $2,000-4,999$ \\
\hline of inhabitants) & & (3) $5,000-19,999$ \\
\hline & & (4) $20,000-49,999$ \\
\hline & & (5) $50,000-99,999$ \\
\hline & & (6) $100,00-499,999$ \\
\hline & & $(7)>500,000(\mathrm{REF})$ \\
\hline
\end{tabular}

Employee structure

Pct. of female

(1) $0-\leq 15$

(1) $0-\leq 15$ (REF)

employees

(2) $>15-\leq 45$

(2) $>15-\leq 45$

(3) $>45-\leq 75$

(3) $>45-\leq 75$ 
Table 1. Continued

Categories

\begin{tabular}{|c|c|c|}
\hline \multirow{2}{*}{ Variable } & \\
\hline & Bias analysis & Regression analysis \\
\hline & (4) $>75-\leq 100$ & (4) $>75-\leq 100$ \\
\hline $\begin{array}{l}\text { Pct. of German } \\
\text { employees }\end{array}$ & $\begin{array}{l}\text { (1) } 0-<100 \\
\text { (2) } 100\end{array}$ & $\begin{array}{l}\text { (1) } 0-<100 \text { (REF) } \\
\text { (2) } 100\end{array}$ \\
\hline $\begin{array}{l}\text { Average age of } \\
\text { employees (years) }\end{array}$ & $\begin{array}{l}\text { (1) } 10.5-\leq 36 \\
\text { (2) }>36-\leq 41 \\
\text { (3) }>41-\leq 45 \\
\text { (4) }>45-\leq 88\end{array}$ & $\begin{array}{l}\text { (1) } 10.5-\leq 36 \text { (REF) } \\
\text { (2) }>36-\leq 41 \\
\text { (3) }>41-\leq 45 \\
\text { (4) }>45-\leq 88\end{array}$ \\
\hline $\begin{array}{l}\text { Pct. of low-qualified } \\
\text { employees }\end{array}$ & $\begin{array}{l}\text { (1) } 0 \\
\text { (2) }>0-\leq 100\end{array}$ & $\begin{array}{l}\text { (1) } 0 \text { (REF) } \\
\text { (2) }>0-\leq 100\end{array}$ \\
\hline $\begin{array}{l}\text { Pct. of middle-qualified } \\
\text { employees }\end{array}$ & $\begin{array}{l}\text { (1) } 0-\leq 50 \\
\text { (2) }>50-\leq 75 \\
\text { (3) }>75-\leq 90 \\
\text { (4) }>90-\leq 100\end{array}$ & $\begin{array}{l}\text { (1) } 0-\leq 50 \text { (REF) } \\
\text { (2) }>50-\leq 75 \\
\text { (3) }>75-\leq 90 \\
\text { (4) }>90-\leq 100\end{array}$ \\
\hline $\begin{array}{l}\text { Pct. of high-qualified } \\
\text { employees }\end{array}$ & $\begin{array}{l}\text { (1) } 0 \\
\text { (2) }>0-\leq 8 \\
\text { (3) }>8-\leq 21 \\
\text { (4) }>21-\leq 100\end{array}$ & $\begin{array}{l}\text { (1) } 0 \text { (REF) } \\
\text { (2) }>0-\leq 8 \\
\text { (3) }>8-\leq 21 \\
\text { (4) }>2-\leq 100\end{array}$ \\
\hline
\end{tabular}

Note: (REF) specifies the reference category for every variable in the logistic regression.

approximately equal-sized groups, or inspection of the original distributions for natural cut-off values with sufficient cell sizes. Three variables (establishment size, location, industry) were categorized slightly differently depending on the type of analysis: bias or regression. Finer categorization was adopted for the regression models. For instance, establishment size, measured by the number of employees, was specified using three categories in the bias analysis (1-9, 10-49, and 50+ employees) and nine categories (from 1-4 to $1000+$ employees) in the regression analysis.

Two additional general characteristics motivated by the literature were considered only in the regression analysis: change in the number of employees since the previous year and area population size (defined as the number of inhabitants in the city or metropolitan area where the establishment resides). The first variable was used as a proxy for the general economic situation by classifying the change in the number of employees from the previous to the current year in three categories: decrease, increase, or no change (Janik 2011). Some establishments had no information from the previous year and were allocated to a missing data category. The use of the second variable was motivated by Phipps and Toth (2012), who identified a correlation between area population size and participation in the aforementioned BLS Occupational Employment Survey.

\section{Methods}

\subsection{Outcome Rate Definitions}

Response and refusal rates were defined by Response Rate 1 and Refusal Rate 1 of the American Association for Public Opinion Research, respectively (AAPOR 2016). The 
noncontact rate was also calculated and based on the same denominator (i.e., all sampled units). By definition, the sum of the refusal and noncontact rates is equal to the total nonresponse rate. By calculating the rates for each year of the IAB Establishment Panel, we analyzed the change in nonresponse over the 17 cross-sections. We note that each cross-section, by definition, excludes existing panel members who are likely to be more cooperative than the general establishment population. Thus, the response rates reported later might be considered as an upper bound compared to a repeated cross-sectional survey without a longitudinal component.

$$
\begin{gathered}
\text { Response rate }_{\text {year }}=\frac{\text { respondent }_{\text {year }}}{\text { sample }_{\text {year }}} \\
\text { Refusal rate }_{\text {year }}=\frac{\text { refusal }_{\text {year }}}{\text { sample }_{\text {year }}} \\
\text { Noncontact rate }_{\text {year }}=\frac{\text { noncontact }_{\text {year }}}{\text { sample }_{\text {year }}}
\end{gathered}
$$

\subsection{Calculation of Nonresponse Biases}

All three types of nonresponse bias (total, refusal, noncontact) were calculated by comparing the estimated percentages of each variable category based on the respondents (or contacts) to the estimate based on the full sample (or contacts) (D'Aurizio and Papadia 2019). For example, nonresponse bias for variable $Y$ was calculated as the difference between the estimated percentage of respondents $r$ belonging to variable category $i$ in year $y: \bar{Y}_{r, i, y}$ and the corresponding percentage estimated for the total sample $n: \bar{Y}_{n, i, y}$. Similarly, for refusal bias, the respondent-based estimate was compared to the estimate based on the contacted cases $c$, and for noncontact bias, the estimates derived from the contacts and full sample were compared:

$$
\begin{gathered}
\text { Nonresponse bias }=\bar{Y}_{r, i, y}-\bar{Y}_{n, i, y} \\
\text { Refusalbias }_{y}=\bar{Y}_{r, i, y}-\bar{Y}_{c, i, y} \\
\text { Noncontact bias }_{y}=\bar{Y}_{c, i, y}-\bar{Y}_{n, i, y}
\end{gathered}
$$

Another way of estimating bias is in relative terms (Sakshaug et al. 2019a; Sakshaug and Huber 2016; Groves 2006). Here, we adopted a measure of absolute relative bias, which assesses the magnitude of the bias relative to its reference estimate:

$$
\begin{gathered}
\text { Absolute relative nonresponse bias } y=\left|\frac{\bar{Y}_{r, i, y}-\bar{Y}_{n, i, y}}{\bar{Y}_{n, i, y}}\right| \\
\text { Absolute relative refusal bias } s_{y}=\left|\frac{\bar{Y}_{r, i, y}-\bar{Y}_{c, i, y}}{\bar{Y}_{c, i, y}}\right| \\
\text { Absolute relative noncontact bias } s_{y}=\left|\frac{\bar{Y}_{c, i, y}-\bar{Y}_{n, i, y}}{\bar{Y}_{n, i, y}}\right|
\end{gathered}
$$

To aid in pointing out particularly large biases, we adopted a subjective cut-off value of $10 \%$ absolute relative bias to define individual biases that might be considered "substantively 
meaningful" (Sakshaug et al. 2019a). However, we acknowledge that such a cut-off is arbitrary and others are likely to have differing opinions regarding such a threshold.

To summarize the results across variable categories and variable groups, the average absolute relative bias is presented. This measure was calculated as the average of the absolute relative bias estimates across all $K$ categories of a relevant variable group:

$$
\begin{gathered}
\text { Average absolute relative nonresponse bias } y=\frac{\sum_{\mathrm{i}=1}^{K}\left|\frac{\bar{Y}_{r, i, y}-\bar{Y}_{n, i, y}}{\bar{Y}_{n, i, y}}\right|}{K} \\
\text { Average absolute relative refusal bias }{ }_{y}=\frac{\sum_{\mathrm{i}=1}^{K}\left|\frac{\mid \bar{Y}_{r, i, y}-\bar{Y}_{c, i, y}}{\bar{Y}_{c, i, y}}\right|}{K} \\
\text { Average absolute relative noncontact bias } \text { bi }_{y}=\frac{\sum_{\mathrm{i}=1}^{K}\left|\frac{\mid \bar{Y}_{c, i, y}-\bar{Y}_{n, i, y}}{\bar{Y}_{n, i, y}}\right|}{K}
\end{gathered}
$$

\subsection{Modeling Survey Participation}

To model survey participation $(1=$ response; $0=$ nonresponse $)$, we run separate logistic regression models on the yearly cross-sectional samples over the entire observation period (i.e., 17 regressions) with the covariates shown in Table 1.

All analyses (outcome rates, nonresponse bias estimation, and regression modeling) were weighted to account for probabilities of selection as establishments with certain characteristics (e.g., larger establishments) were routinely oversampled in each crosssectional sample. The analyses were performed using the "survey" commands in Stata 15 (StataCorp 2017).

\section{Results}

\subsection{Outcome Rate Trends}

Figure 1 shows the response rate, refusal rate, and noncontact rate for each of the corresponding years. Changes in the outcome rates were observed over the 17-year observation period. The response rate reduced by nearly a third from $50.2 \%$ (2001) to

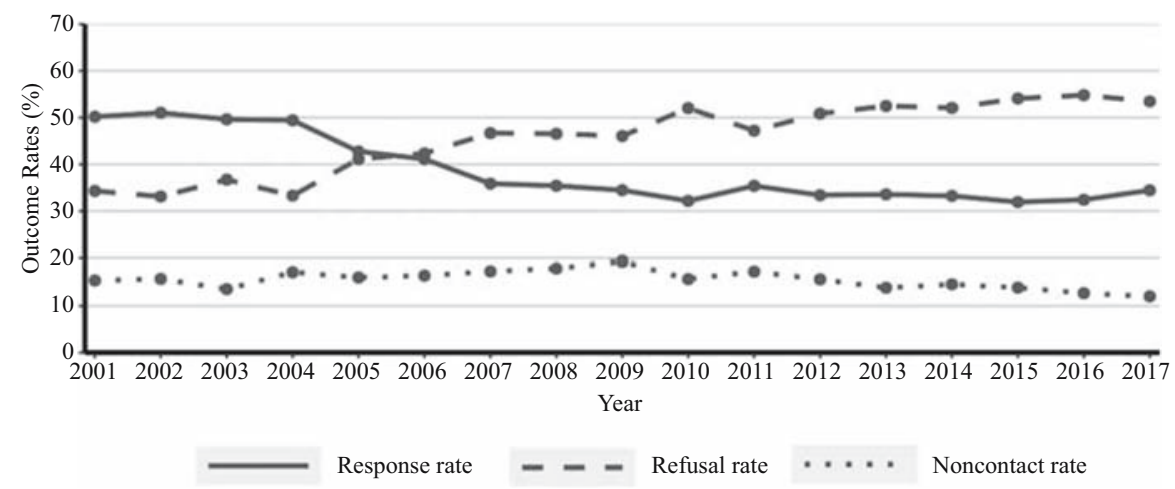

Fig. 1. Outcome rates in the cross-sectional samples of the IAB establishment panel by survey year. 
$34.5 \%$ (2017), an average yearly decline of about $1 \%$. A closer look reveals that the largest decrease in the response rate of about 13.6\% took place between 2004 and 2007, an average decrease of $4.5 \%$ per year. Since 2007 , the response rate has been mostly stable and reached a low point of $31.9 \%$ in 2015 . The declining response is mainly driven by refusals rather than noncontacts. While the noncontact rate fluctuated slightly around $15 \%$, peaked at $19.4 \%$ in 2009 , and decreased slightly since 2011 , the share of refusals trended upward from $34.3 \%$ (2001) to $53.5 \%$ (2017). It is evident that the decrease in response is primarily explained by an increasing share of refusing establishments.

\subsection{Nonresponse Bias Trends}

Since a temporal change in the outcome rates was found, possible consequences in the form of compositional distortions in the respondent pool (i.e., nonresponse bias) may exist. We examined this possibility by first looking at nonresponse bias, followed by refusal and noncontact bias. Figure 2 depicts the average absolute relative nonresponse bias for the two summary variable groups (general characteristics and employee structure) and overall (for the tabular version, see online supplemental material Table S3). In general, there was an increasing average nonresponse bias overall and for both variable groups. The overall absolute relative nonresponse bias ranged from $5.23 \%$ in 2001 to $8.34 \%$ in 2017 - an overall increase of about $60 \%$ - with a low point of $2.95 \%$ in 2004.

A comparison of the variable groups revealed that the average biases were similar across groups, but showed some minor differences. General characteristics displayed the greatest range of $6.16 \%$ (2001) and 9.42\% (2017), closely followed by employee structure with a range of $4.67 \%$ (2001) and $7.68 \%$ (2017). The percentage increases in the average bias of these variable groups were $53 \%$ and $65 \%$, respectively, over the entire 17-year observation period. In summary, the aggregated nonresponse biases had a mostly increasing trend over the observation period.

The absolute relative nonresponse bias for each individual variable category is presented in online supplemental material Table S4. Among the general establishment characteristics, establishment size stood out the most. The largest absolute relative nonresponse bias, which ranged from $2.54 \%$ (2001) to $35.45 \%$ (2017), was observed for the category $50+$ employees. Likewise, the relative bias for the 1-9 employees' category showed an increasing trend, but

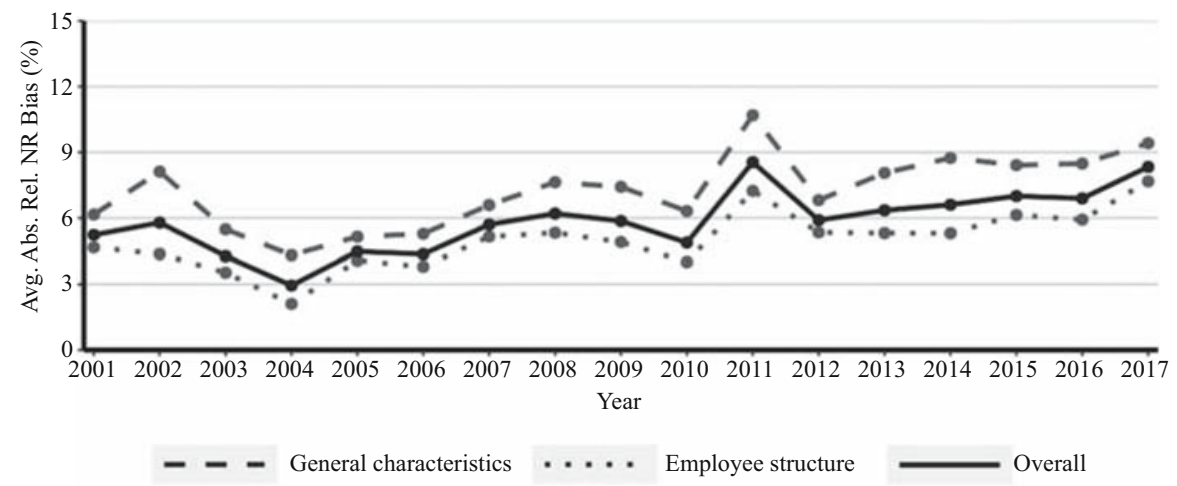

Fig. 2. Average absolute relative nonresponse bias of the summary variable groups and overall. 
never exceeded $8 \%$. Furthermore, the industry category agriculture/production displayed large relative bias values (often exceeding 10\%), but no clear time trend was identified.

Regarding the employee structure group, establishments with $0-8 \%$ high-qualified employees had the largest growth in absolute relative nonresponse bias, ranging from $0.90 \%$ to $23.29 \%$ in 2001 and 2017 , respectively. All other categories did not show a distinct pattern over the observation period and exceeded $10 \%$ relative bias only occasionally. The relative bias for the category of establishments with $100 \%$ German employees steadily rose over the observation period but never exceeded $10 \%$.

Figure 3 displays the trends of average absolute relative refusal bias (for the tabular version, see online supplemental material Table S5). The results show that the pattern of refusal bias is similar to nonresponse bias with mostly slightly larger values. The overall average absolute relative refusal bias has more than doubled, with a range between $4.90 \%$ (2001) and 10.02\% (2017). Thus, the increase in overall refusal bias was much larger than that of overall nonresponse bias.

Each variable group showed an increase in the refusal bias over the observation period, but a noteworthy difference between them is not readily apparent. However, it has to be highlighted that the employee structure group showed a larger overall increase in average refusal bias over the observation period than the general characteristics group. The trends for the single category refusal biases (online supplemental material Table S6) largely resembled their corresponding total relative nonresponse bias trends.

Figure 4 depicts the average absolute relative noncontact bias, which does not show any distinct trend (for the tabular version, see online supplemental material Table S7). The average absolute relative noncontact bias has declined from 5.31\% in 2001 to $3.55 \%$ in 2017. Additionally, the average absolute relative noncontact biases for the two variable groups hardly differed. Only for the individual variable category $50+$ employees was the relative noncontact bias noticeable (online supplemental material Table S8). The relative noncontact bias exceeded $10 \%$ in most years, but no increasing or decreasing trend was observed. In summary, noncontact bias was unremarkable compared to the refusal and overall nonresponse biases. The overall nonresponse bias, which increased especially in later years, was therefore mainly driven by an increasing refusal bias over time.

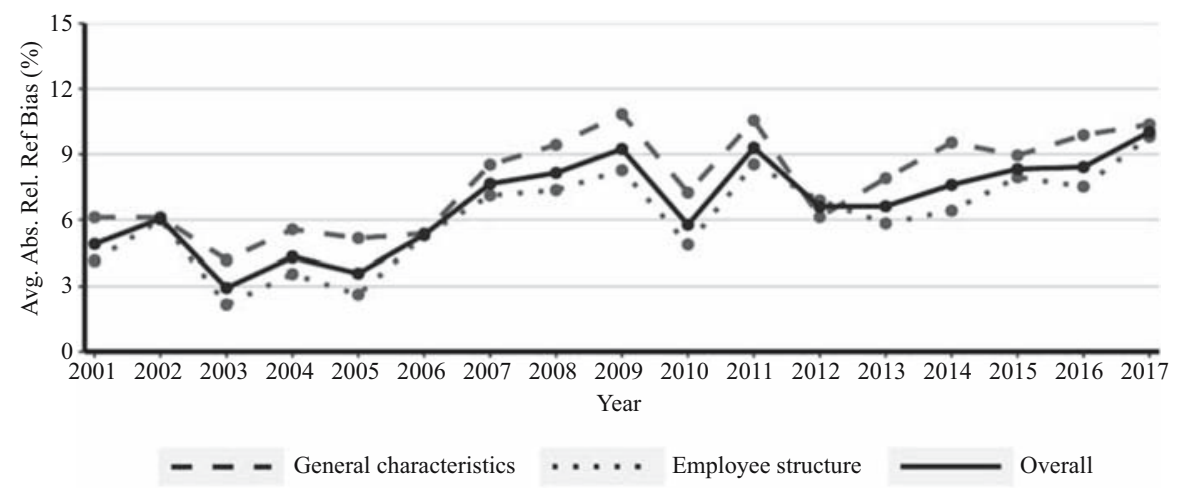

Fig. 3. Average absolute relative refusal bias of the summary variable groups and overall. 


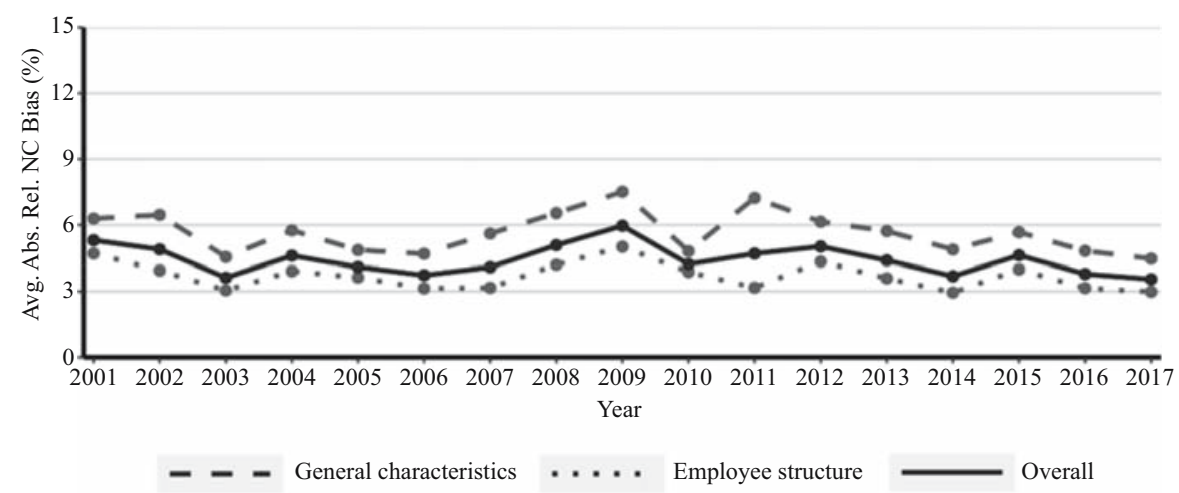

Fig. 4. Average absolute relative noncontact bias of the summary variable groups and overall.

To gain a deeper insight into the relationship between the nonresponse rate and nonresponse bias, we examined whether a correlation exists in the IAB Establishment Panel. We correlated the nonresponse rate to the individual bias values for each variable category of the same year. Figure 5 displays the nonresponse rate against the absolute relative nonresponse biases for all 29 variable categories. The overall correlation coefficient is 0.15 indicating a weak positive correlation. This correlation is consistent with studies from the household survey literature, which also found a small positive correlation, indicating that as the nonresponse rate increases so does the potential for nonresponse bias (Groves 2006; Groves and Peytcheva 2008).

\subsection{Trends in the Likelihood of Participation}

The third research question concerns the extent to which establishment characteristics are associated with survey participation and whether such associations change over time. Table 2 shows the averaged results of the 17 logistic regression models for year-specific survey participation conditional on the administrative predictor variables, and the number of times the predictor variables were statistically significant $(p<0.05)$ across all models. To simplify the presentation, average marginal effects (AMEs) are shown, which are

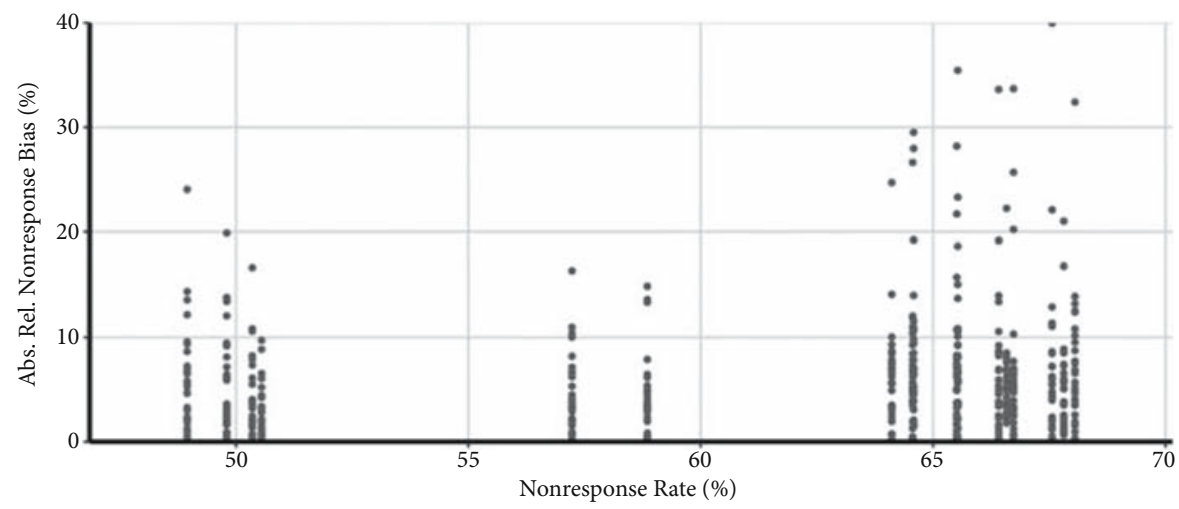

Fig. 5. Percentage absolute relative nonresponse bias of every variable category by the nonresponse rate of the same year. 
interpreted as the average probability of response for each covariate compared to its reference group (Kohler and Kreuter 2012). The mean AMEs provide a summary impression of the association between establishment characteristics and survey participation across the 17 years. The range of all estimates is between -0.20 and 0.16 . In general, most mean AME values are small and many are close to 0 , which means that they did not have a strong influence on participation.

Out of all the predictors, establishment size had the largest negative influence on survey participation: establishments with more than 1,000 employees had an average probability of response that was 0.20 lower than establishments with 1-4 employees. The mean AME values show a consistent pattern that the likelihood to participate decreased with an increasing number of employees. The largest positive average AME value (0.16) was attributed to establishments located in areas with less than 20,000 inhabitants, suggesting that these establishments were more likely to participate than establishments located in areas with more than 500,000 inhabitants. Overall, area population showed a homogenous trend as the likelihood of participation decreased with increasing area population size.

The industry of an establishment also showed some significant effects across years. For example, establishments in the transport and communication industry were, on average, less likely (-0.08) to participate than those in the manufacturing industry (reference). Additionally, the services for companies industry showed more significant AME values than other industries, which resulted in a mean AME of -0.08. Furthermore, establishments in West and North Germany were less likely to participate ( -0.05 and -0.03 , respectively), on average, compared to those in East Germany. For establishments in South Germany the mean AME showed almost no difference in the response propensity compared to East Germany. The variable regarding changes in the number of employees from the previous to the current year, which is a proxy for the general economic conditions of an establishment's environment, was not strongly related to survey participation as the mean AME values were close to zero and rarely statistically significant in the year-specific models.

The employee structure predictors, which reflect the social demographics of the employees, showed mainly very small effects on participation, and rarely were these predictors statistically significant in the regression models. The strongest predictor that was most often significant in this group over the observation period was the percentage of German employees: establishments with only German employees were more likely (0.04) to participate than those that also employ non-Germans.

Lastly, we examined trends in the regression estimates over time. As the mean AMEs already indicated, the magnitudes of the coefficient estimates were small, and many predictors were not statistically significant in most years. Thus, for most variables, no reliable increasing or decreasing trend was observed over time. As an example, the yearspecific AME values for the variable establishment size, which showed the largest average negative AME, are interpreted here (for full results, see online supplemental material Figure S1). In most years the AMEs for this variable were statistically significant, especially if the establishment had 20 or more employees; however, the trends were rather stable with minor fluctuations and did not show any increasing or decreasing shifts over time. One exception which showed a remarkable trend over time was location of establishment. As depicted in Figure 6, the impact of the location on survey participation changed over the years. In particular, establishments in South and North Germany showed 
Table 2. Mean average marginal effects (AMEs) of logistic regression models of survey participation for years 2001 to 2017.

\begin{tabular}{|c|c|c|c|}
\hline Variable & Category & $\begin{array}{l}\text { Mean } \\
\text { AME }\end{array}$ & $\begin{array}{l}\text { Number of statistically } \\
\text { significant AME values } \\
\text { across all } 17 \text { models } \\
\quad(\mathrm{p}<0.05)\end{array}$ \\
\hline \multicolumn{4}{|c|}{ General characteristics } \\
\hline \multirow[t]{4}{*}{ Location } & East Germany & \multicolumn{2}{|r|}{ REF } \\
\hline & South Germany & 0.002 & 5 \\
\hline & North Germany & -0.03 & 10 \\
\hline & West Germany & -0.05 & 14 \\
\hline \multirow{9}{*}{$\begin{array}{l}\text { Establishment size } \\
\text { (number of } \\
\text { employees) }\end{array}$} & $1-4$ & \multicolumn{2}{|r|}{ REF } \\
\hline & $5-9$ & -0.01 & 5 \\
\hline & $10-19$ & -0.03 & 5 \\
\hline & $20-49$ & -0.05 & 10 \\
\hline & $50-99$ & -0.07 & 13 \\
\hline & $100-199$ & -0.10 & 12 \\
\hline & $200-499$ & -0.12 & 13 \\
\hline & $500-999$ & -0.16 & 15 \\
\hline & $1,000+$ & -0.20 & 13 \\
\hline \multirow[t]{9}{*}{ Industry } & $\begin{array}{l}\text { Agriculture/mining/ } \\
\text { energy/water }\end{array}$ & 0.03 & 4 \\
\hline & $\begin{array}{l}\text { Manufacturing } \\
\text { industry }\end{array}$ & \multicolumn{2}{|r|}{ REF } \\
\hline & $\begin{array}{l}\text { Construction } \\
\text { industry }\end{array}$ & -0.03 & 4 \\
\hline & Trade/repair & -0.05 & 9 \\
\hline & $\begin{array}{l}\text { Transport/ } \\
\text { communication }\end{array}$ & -0.08 & 13 \\
\hline & $\begin{array}{l}\text { Financial } \\
\text { intermediation }\end{array}$ & -0.05 & 7 \\
\hline & $\begin{array}{l}\text { Services mainly } \\
\text { for companies }\end{array}$ & -0.08 & 12 \\
\hline & Other services & -0.007 & 8 \\
\hline & Public sector & -0.02 & 2 \\
\hline \multirow[t]{4}{*}{ Year of foundation } & 1970s/1980s & 0.02 & 3 \\
\hline & $1990 \mathrm{~s}$ & 0.003 & 3 \\
\hline & $2000 \mathrm{~s}$ & \multicolumn{2}{|r|}{ REF } \\
\hline & Unknown & 0.02 & 2 \\
\hline \multirow{4}{*}{$\begin{array}{l}\text { Change in the number } \\
\text { of employees since } \\
\text { previous year }\end{array}$} & Decrease & -0.02 & 2 \\
\hline & No change & \multicolumn{2}{|r|}{ REF } \\
\hline & Increase & 0.01 & 2 \\
\hline & Unknown & -0.01 & 3 \\
\hline \multirow{7}{*}{$\begin{array}{l}\text { Area population size } \\
\text { (number of } \\
\text { inhabitants) }\end{array}$} & $<2,000$ & 0.16 & 14 \\
\hline & $2,000-4,999$ & 0.16 & 16 \\
\hline & $5,000-19,999$ & 0.16 & 17 \\
\hline & $20,000-49,999$ & 0.13 & 16 \\
\hline & $50,000-99,999$ & 0.12 & 15 \\
\hline & $100,00-499,999$ & 0.09 & 17 \\
\hline & $>500,000$ & \multicolumn{2}{|r|}{ REF } \\
\hline
\end{tabular}




\begin{tabular}{|c|c|c|c|}
\hline Variable & Category & $\begin{array}{l}\text { Mean } \\
\text { AME }\end{array}$ & $\begin{array}{l}\text { Number of statistically } \\
\text { significant AME values } \\
\text { across all } 17 \text { models } \\
\quad(\mathrm{p}<0.05)\end{array}$ \\
\hline \multicolumn{4}{|c|}{ Employee structure } \\
\hline $\begin{array}{l}\text { Pct. of female } \\
\text { employees }\end{array}$ & $\begin{array}{l}0-15 \\
>15-45 \\
>45-75 \\
>75-100\end{array}$ & $\begin{array}{l}0.02 \\
0.03 \\
0.02\end{array}$ & REF \\
\hline $\begin{array}{l}\text { Pct. of German } \\
\text { employees }\end{array}$ & $\begin{array}{l}0-<100 \\
100\end{array}$ & 0.04 & $\begin{array}{ll}\text { REF } & \\
& 12\end{array}$ \\
\hline $\begin{array}{l}\text { Average age of } \\
\text { employees (years) }\end{array}$ & $\begin{array}{l}10,5-36 \\
>36-41 \\
>41-45 \\
>45-88\end{array}$ & $\begin{array}{l}-0.01 \\
-0.007 \\
-0.005\end{array}$ & $\begin{array}{ll}\text { REF } & \\
& 2 \\
& 0 \\
1\end{array}$ \\
\hline $\begin{array}{l}\text { Pct. of low-qualified } \\
\text { employees }\end{array}$ & $\begin{array}{l}0 \\
>0-100\end{array}$ & 0.001 & REF \\
\hline $\begin{array}{l}\text { Pct. of middle-qualified } \\
\text { employees }\end{array}$ & $\begin{array}{l}0-50 \\
>50-75 \\
>75-90 \\
>90-100\end{array}$ & $\begin{array}{c}0.003 \\
0.01 \\
0.01\end{array}$ & $\begin{array}{l}1 \\
0 \\
2\end{array}$ \\
\hline $\begin{array}{l}\text { Pct. of high-qualified } \\
\text { employees }\end{array}$ & $\begin{array}{l}0 \\
>0-8 \\
>8-21 \\
>21-100\end{array}$ & $\begin{array}{l}0.01 \\
0.01 \\
0.01\end{array}$ & $\begin{array}{ll}\text { REF } & \\
& 0 \\
2 \\
5\end{array}$ \\
\hline
\end{tabular}

Note: REF specifies the reference category for every variable in the logistic regression.

increasingly positive AMEs for later years, that is, these establishments became increasingly more likely to respond over time compared to establishments in East Germany. For establishments in West Germany the trend was less consistent. All other predictors did not show any notable increasing or decreasing trends in their AMEs over time (see online supplemental material Figures S2-S11).

\section{Discussion}

This study examined trends in response rates and nonresponse bias in the IAB Establishment Panel's yearly cross-sectional samples from 2001 to 2017 and yielded three main findings. First, we found that yearly response rates decreased by almost a third from $50.2 \%$ in 2001 to $34.5 \%$ in 2017, with the largest decrease of $13.6 \%$ from 2004 to 2007. While the noncontact rate fluctuated almost evenly, the refusal rate steadily rose over this period and was the main driver of nonresponse. Second, the average absolute relative nonresponse bias, measured across 29 individual estimates, increased over the same period from $5.23 \%$ to $8.34 \%$, an increase of about $60 \%$. The largest increase in aggregate nonresponse bias was observed for estimates related to the establishments' employee structure (65\% increase), followed by general characteristics of the establishments $(53 \%)$. 


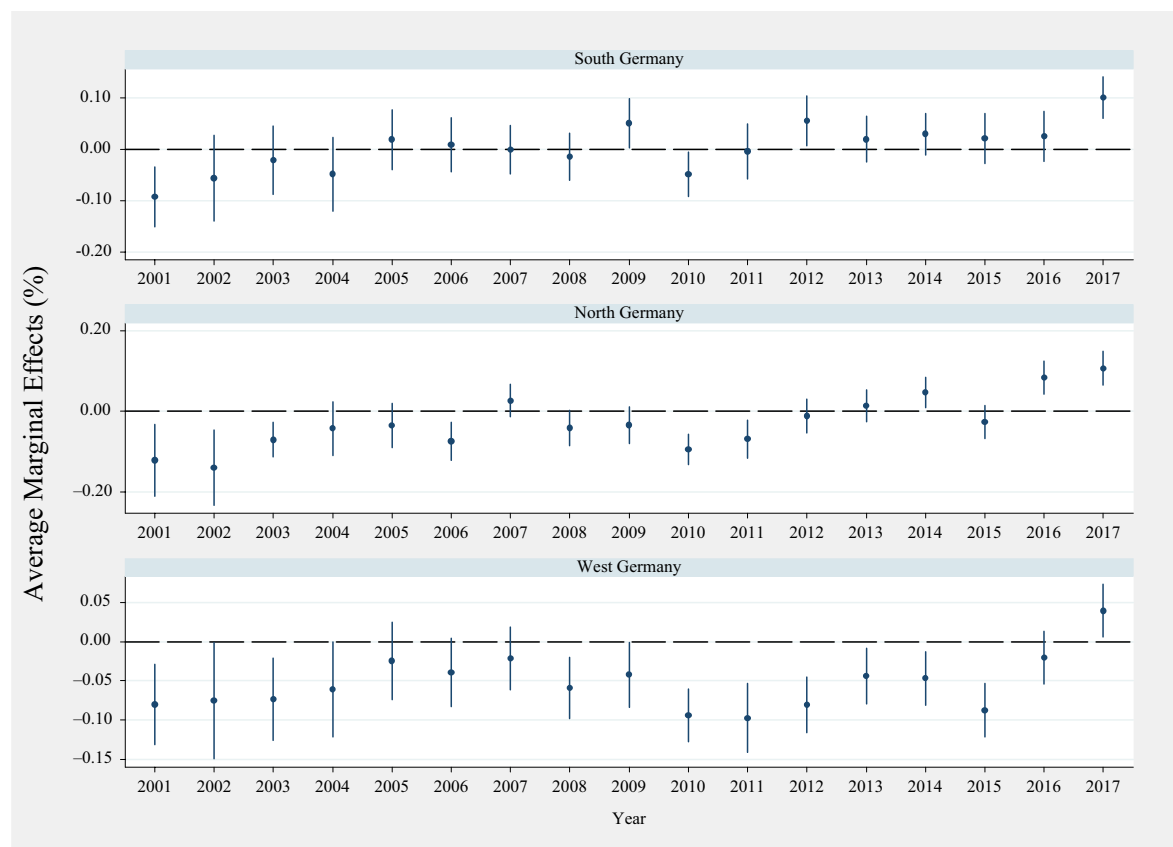

Fig. 6. Average marginal effects and $95 \%$ confidence intervals by year for the variable: Location (reference category: East Germany).

By separately considering noncontact and refusal bias, it became evident that the latter bias was the primary driver of the growth in nonresponse bias. A rather low positive correlation of 0.15 was found for the nonresponse rate and the absolute relative nonresponse biases for the same year, which corresponded to the small positive correlations found in the household survey literature (Groves 2006; Groves and Peytcheva 2008). Lastly, we found only few consistently strong predictors of survey participation across the 17-year observation period. Specifically, larger establishments with more than 1,000 employees were less likely to participate compared to smaller establishments. Furthermore, establishments located in smaller area population sizes were more likely to participate. Both relationships were relatively consistent over time, with minor fluctuations.

The declining response rate trend that we found in the repeated cross-sectional IAB Establishment Panel surveys is consistent with trends observed in household surveys, which generally showed declining response rates in recent years (e.g., Luiten et al. 2020; Beullens et al. 2018; Brick and Williams 2013). This is remarkable given that the survey participation decision among establishments is unique to the decision-making process among households. Our findings are also in line with Janik (2011) and Seiler (2010) who found that a change in the number of employees from the previous to the current year, which is a proxy for the general economic conditions of an establishment's environment, did not affect survey participation. Furthermore, we found evidence supporting the results of Phipps and Toth (2012), who ascertained that establishments located in large cities with more than one million inhabitants were less likely to participate compared to those located in smaller cities. Our results suggested this pattern also held for establishments in cities with more than 500,000 inhabitants. Finally, our results regarding establishment size 
agreed with other findings showing that the likelihood of survey participation decreases with increasing number of employees (Earp et al. 2018; Phipps and Toth 2012; Janik 2011; Tomaskovic-Devey et al. 1995).

The present study further examined new predictors of survey participation, focusing not only on general establishment characteristics, but also on the composition of the establishments' employee structure. The results indicated that establishments with only German employees were slightly more likely to participate than establishments that also employ non-Germans. However, other predictors, such as the shares of female or middlequalified employees, did not show consistently strong effects.

The strengths of the present study included the long observation period of 17 years and the rich administrative data available for analyzing nonresponse bias in each of the yearly cross-sectional samples. Nevertheless, some study limitations must be acknowledged. Namely, we considered only one data source, the IAB Establishment Panel, a large faceto-face survey based in Germany. The study results must therefore be interpreted with caution when generalizing them to other studies, countries, and data collection modes. Furthermore, it is important to note that the establishment characteristics considered in our participation models do not fully explain the internal decision-making processes that occur within an establishment. For example, larger establishments may have stricter participation policies for non-mandatory surveys compared to smaller establishments. In addition, larger establishments likely have more complex internal decision-making processes and more difficulties finding the best respondent and accessing the requested information. Including more detailed information about these internal processes would undoubtedly improve the explanatory power of establishment participation models (Bavdaz et al. 2019; Willimack and Nichols 2010; Fisher et al. 2003; Willimack et al. 2002).

In conclusion, the results provide evidence that large establishments are strongly underrepresented in voluntary surveys. Since these establishments have a larger impact on the resulting statistics compared to smaller ones, it is critical that the field of business survey methodology focus efforts on addressing this issue. One possible research direction in this context is the use of incentives to motivate participation (Dillman et al. 2014; Beckler and Ott 2006; Jobber et al. 1991). For example, survey sponsors might consider offering larger establishments detailed personalized reports of the study results showing how their establishment compares to other establishments in similar locations or industries (Luo and White 2005). Another approach is to tailor the recruitment procedure for the very large establishments, as they likely require special treatment. Specifically, voluntary surveys may benefit from borrowing from the recruitment strategies commonly used in mandatory surveys, such as providing personalized support and persistent follow-ups to the largest establishments through the use of a dedicated team of survey specialists and subject-matter experts who recruit and assist establishments throughout the entire survey process.

\section{References}

AAPOR (American Association for Public Opinion research). 2016. Standard Definitions: Final Dispositions of Case Codes and Outcome Rates for Surveys. AAPOR. 
Bavdaz, M., D. Giesen, D.L. Moore, P.A. Smith, and J. Jones. 2019. “Qualitative Testing for Official Establishment Survey Questionnaires". Survey Research Methods 13(3): 267-288. DOI: https://doi.org/10.18148/srm/2019.v13i3.7366.

Beckler, D.G., and K. Ott. 2006. "Indirect Monetary Incentives with a Complex Agricultural Establishment Survey”. In Proceedings of the American Statistical Association, Survey Research Methodology Section, 2741-2748. Alexandria, VA, USA. American Statistical Association. Available at: http://citeseerx.ist.psu.edu/viewdoc/ download doi $=10.1 .1 .511 .9782 \& r e p=$ rep1\&type $=$ pdf $($ accessed November 2021$)$.

Beullens, K., G. Loosveldt, C. Vandenplas, and I. Stoop. 2018. "Response Rates in the European Social Survey: Increasing, Decreasing, or a Matter of Fieldwork Efforts?" Survey Methods: Insights from the Field: 1-12. DOI: https://doi.org/10.13094/SMIF2018-00003.

Brick, J.M., and R. Tourangeau. 2017. "Responsive Survey Designs for Reducing Nonresponse Bias." Journal of Official Statistics 33(3): 735-752. DOI: http://dx.doi. org/10.1515/JOS-2017-0034.

Brick, J.M., and D. Williams. 2013. "Explaining Rising Nonresponse Rates in Crosssectional Surveys." In The Annals of the American Academy of Political and Social Science 645: 36-59. DOI: https://doi.org/10.1177/0002716212456834.

Brixy, U., S. Kohaut, and C. Schnabel. 2007. "Do Newly Founded Firms Pay Lower Wages? First Evidence from Germany.” Small Business Economics 29(1-2): 161-171. DOI: https://doi.org/10.1007/s11187-006-0015-x.

Christianson, A., and R.D. Tortora. 1995. "Issues in Surveying Businesses: An International Survey.” In Business Survey Methods, 235-256. New York: John Wiley \& Sons. DOI: https://doi.org/10.1002/9781118150504.ch14.

D’Aurizio, L., and G. Papadia. 2019. "Using Administrative Data to Evaluate Sampling Bias in a Business Panel Survey." Journal of Official Statistics 35(1): 67-92. DOI: https://doi.org/10.2478/jos-2019-0004.

Davis, W.R., and N. Pihama. 2009. "Survey Response as Organisational Behaviour: An Analysis of the Annual Enterprise Survey 2003-2007." New Zealand Association of Economists Conference 2009: 1-16. Wellington, New Zealand: New Zeland Association of Economists. Available at: https://ro.uow.edu.au/eispapers/826/ (accessed November 2021).

De Leeuw, E., and W. de Heer. 2002. "Trends in Household Survey Nonresponse: A Longitudinal and International Comparison." In Survey Nonresponse, edited by R.M. Groves, D.A. Dillman, J.L. Eltinge, and R.J.A. Little, 41-54. New York: Wiley.

Dillman, D.A., J.D. Smyth, and L.M. Christian. 2014. Internet, Phone, Mail, and MixedMode Surveys: The Tailored Design Method. New York: John Wiley \& Sons.

Earp, M., D. Toth, P. Phipps, and C. Oslund. 2018. "Assessing Nonresponse in a Longitudinal Establishment Survey Using Regression Trees." Journal of Official Statistics 34(2): 463-481. DOI: https://doi.org/10.2478/jos-2018-0021.

Ellguth, P., S. Kohaut, and I. Möller. 2013. "The IAB Establishment Panel Methodological Essentials and Data Quality." Journal for Labour Market Research 47: 27-41. DOI: https://doi.org/10.1007/s12651-013-0151-0. 
Ellguth, P., and S. Kohaut. 2019. "A Note on the Decline of Collective Bargaining Coverage: The Role of Structural Change." Jahrbücher für Nationalökonomie und Statistik 239(1): 39-66. DOI: https://doi.org/10.1515/jbnst-2017-0163.

Eurofound. 2015. Third European Company Survey - Overview Report: Workplace Practices - Patterns, Performance and Well-Being. Luxembourg: Publications Office of the European Union. Available at: https://www.eurofound.europa.eu/sites/default/files/ef_publication/field_ef_document/ef1502en_0.pdf (accessed November 2021).

Fischer, G., F. Janik, D. Müller, and A. Schmucker. 2008. “The IAB Establishment Panel from Sample to Survey to Projection.” FDZ Methodenreport 01/2008: Nuremberg. Available at: https://core.ac.uk/reader/6561380 (accessed November 2021).

Fisher, S., J. Bosley, K. Goldenberg, W. Mockovak, and C. Tucker. 2003. "A Qualitative Study of Nonresponse Factors Affecting BLS Establishment Surveys: Results." Presented at the Annual Joint Statistical Meetings, San Francisco, CA. Available at: https://www.bls.gov/osmr/research-papers/2003/pdf/st030230.pdf (accessed November 1st 2021).

Groves, R.M. 2006. "Nonresponse Rates and Nonresponse Bias in Household Surveys." Public Opinion Quarterly 70(5): 646-675. DOI: https://doi.org/10.1093/poq/nfl033.

Groves, R.M., and M.P. Couper. 1998. Nonresponse in Household Interview Surveys. New York: John Wiley \& Sons.

Groves, R.M., and E. Peytcheva. 2008. "The Impact of Nonresponse Rates on Nonresponse Bias: A Meta-Analysis.” Public Opinion Quarterly 72(2): 167-189. DOI: https://doi.org/10.1093/poq/nfn011.

Henze, p. 2014. "Structural Change and Wage Inequality: Evidence from German Micro Data." Center for European, Governance and Economic Development Research Working Paper 204. DOI: http://dx.doi.org/10.2139/ssrn.2422471.

Janik, F. 2011. "Unit Non-response in Establishments Surveyed for the First Time in the IAB Establishment Panel.” FDZ Methodenreport 04/2011: Nuremberg. Available at: https://www.researchgate.net/publication/228956272_Unit_non-response_in_establishments_surveyed_for_the_first_time_in_the_IAB_Establishment_Panel (accessed November 2021).

Janik, F., and S. Kohaut. 2012 "Why Don't They Answer? Unit Non-response in the IAB Establishment Panel.” Quality \& Quantity 46: 917-934. DOI: https://doi.org/10.1007/ s11135-011-9436-y.

Jobber, D., H. Mirza, and K.H. Wee. 1991. "Incentives and Response Rates to Crossnational Business Surveys: A Logit Model Analysis.” Journal of International Business Studies 22: 711-721. DOI: https://doi.org/10.1057/palgrave.jibs.8490852.

Kohler, U., and F. Kreuter. 2012. Datenanalyse mit Stata: Allgemeine Konzepte der Datenanalyse und ihre praktische Anwendung. München: Oldenbourg.

Luiten, A., J Hox, and E. de Leeuw. 2020. "Survey Nonresponse Trends and Fieldwork Effort in the 21st Century: Results of an International Study across Countries and Surveys." Journal of Official Statistics 36(3): 469-487. DOI: http://dx.doi.org/10.2478/ JOS-2020-0025.

Luo, A., and G.D. White. 2005. "Exploring a New Establishment Survey Incentive to Improve Response Rates." In Proceedings of the American Statistical Association, Survey Research Methodology Section, May 12-15, 2005. 3915-3918. Miami Beach, 
Florida. American Statistical Association. Available at: http://citeseerx.ist.psu.edu/ viewdoc/download?doi $=10.1 .1 .528 .9845 \& \mathrm{rep}=$ rep1\&type $=$ pdf $($ accessed November 2021).

Mullins, J.P. 2016. "One Hundred Years of Current Employment Statistics - an Overview of Survey Advancements.” Monthly Labor Review. DOI: https://doi.org/10.21916/mlr. 2016.39.

Paxson, M.C., D.A. Dillman, and J. Tarnai. 1995. "Improving Response to Business Mail Surveys." In Business Survey Methods, edited by B.G. Cox, D.A. Binder, B.N. Chinnappa, A. Christianson, M.J. Colledge, and P.S. Kott, 303-316. New York: Wiley. Petroni, R., R. Sigman, D. Willimack, S. Cohen, and C. Tucker. 2004 "Response Rates and Nonresponse in Establishment Surveys-BLS and Census Bureau." Presented to the Federal Economic Statistics Advisory Committee, 1-50. Available at: http://citeseerx. ist.psu.edu/viewdoc/download?doi $=10.1 .1 .485 .5983 \& \mathrm{rep}=$ rep1\&type $=$ pdf (accessed November 2021).

Phipps, P., and D. Toth. 2012. "Analyzing Establishment Nonresponse Using an Interpretable Regression Tree Model with Linked Administrative Data." The Annals of Applied Statistics 6(2): 772-794. DOI: https://doi.org/10.1214/11-AOAS521.

Sakshaug, J.W., and M. Huber. 2016. "An Evaluation of Panel Nonresponse and Linkage Consent Bias in a Survey of Employees in Germany." Journal of Survey Statistics and Methodology 4(1): 71-93. DOI: https://doi.org/10.1093/jssam/smv034.

Sakshaug, J.W., S. Hülle, A. Schmucker, and S. Liebig. 2019a. "Panel Survey Recruitment With or Without Interviewers? - Implications for Nonresponse Bias, Panel Consent Bias, and Total Recruitment Bias.” Journal of Survey Statistics and Methodology 8(3): 540-565. DOI: https://doi.org/10.1093/jssam/smz012.

Sakshaug, J.W., B. Vicari, and M.P. Couper. 2019b. "Paper, E-mail, or Both? Effects of Contact Mode on Participation in a Web Survey of Establishments." Social Science Computer Review 37(6): 750-765. DOI: https://doi.org/10.1177/0894439318805160.

Schmucker, A., A. Ganzer, J. Stegmaier, and S. Wolter. 2018. "Establishment History Panel 1975-2017." FDZ Datenreport 09/2018: Nuremberg. DOI: https://doi.org/10. 5164/IAB.FDZD.1809.en.v1.

Seiler, C. 2010. "Dynamic Modelling of Nonresponse in Business Surveys.” Ifo Working Paper No. 93. Munich: ifo Institute - Leibniz Institute for Economic Research at the University of Munich. Available at: https://www.econstor.eu/bitstream/10419/73706/1/ IfoWorkingPaper-93.pdf (accessed November 2021).

StataCorp. 2017. Stata Statistical Software: Release 15. College Station, TX: StataCorp LLC.

Sudman, S., D.K. Willimack, E. Nichols, and T.L. Mesenbourg. 2000. "Exploratory Research at the U.S. Census Bureau on the Survey Response Process in Large Companies." In Proceedings of the Second International Conference on Establishment Surveys, June 17-21, 2000: 327-337. Buffalo, New York. American Statistical Association.

Tomaskovic-Devey, D., J. Leiter, and S. Thompson. 1995. "Item Nonresponse in Organizational Surveys.” Sociological Methodology 25: 77-110. DOI: https://doi.org/ $10.2307 / 271062$. 
Wagner, J. 2012. “Average Wage, Qualification of the Workforce and Export Performance in German Enterprises: Evidence from KombiFiD Data." Journal for Labour Market Research 45: 161-170. DOI: https://doi.org/10.1007/s12651-012-0106-x.

Willimack, D.K., E. Nichols, and S. Sudman. 2002. "Understanding Unit and Item Nonresponse in Business Surveys." In Survey Nonresponse, edited by R.M. Groves, D.A. Dillman, J.L. Eltinge, and R.J.A. Little, 213-227. New York: Wiley.

Willimack, D.K., and E. Nichols. 2010. "A Hybrid Response Process Model for Business Surveys.” Journal of Official Statistics 26 (1): 3-24. Available at: https://www.scb.se/contentassets/f6bcee6f397c4fd68db6452fc9643e68/a-hybrid-response-process-modelfor-business-surveys.pdf\%20 (accessed November 2021).

Willimack, D.K., and G. Snijkers. 2013. "The Business Context and Its Implications for the Survey Response Process." In Designing and Conducting Business Surveys, edited by G. Snijkers, G. Haraldsen, J. Jones, and D.K. Willimack, 39-82. Hoboken, NJ: John Wiley \& Sons.

Received September 2020

Revised December 2020

Accepted March 2021 